\title{
A Bias in the Midtropospheric Channel Warm Target Factor on the NOAA-9 Microwave Sounding Unit
}

\author{
STEPHEN Po-Chedley AND QIANG Fu \\ Department of Atmospheric Sciences, University of Washington, Seattle, Washington
}

(Manuscript received 2 September 2011, in final form 28 November 2011)

\begin{abstract}
The University of Alabama at Huntsville (UAH), Remote Sensing Systems (RSS), and the National Oceanic and Atmospheric Administration (NOAA) have constructed long-term temperature records for deep atmospheric layers using satellite Microwave Sounding Unit (MSU) and Advanced Microwave Sounding Unit (AMSU) observations. However, these groups disagree on the magnitude of global temperature trends since 1979, including the trend for the midtropospheric layer (TMT). This study evaluates the selection of the MSU TMT warm target factor for the NOAA-9 satellite using five homogenized radiosonde products as references. The analysis reveals that the UAH TMT product has a positive bias of $0.051 \pm 0.031$ in the warm target factor that artificially reduces the global TMT trend by $0.042 \mathrm{~K} \mathrm{decade}^{-1}$ for $1979-2009$. Accounting for this bias increases the global UAH TMT trend from 0.038 to $0.080 \mathrm{~K} \mathrm{decade}^{-1}$, effectively eliminating the trend difference between UAH and RSS and decreasing the trend difference between UAH and NOAA by $47 \%$. This warm target factor bias directly affects the UAH lower tropospheric (TLT) product and tropospheric temperature trends derived from a combination of TMT and lower stratospheric (TLS) channels.
\end{abstract}

\section{Introduction}

A great deal of attention has been focused on model versus satellite-derived temperature trends in the troposphere (e.g., Karl et al. 2006; Solomon et al. 2007; Santer et al. 2008; Christy et al. 2010; Fu et al. 2011). The satellite-derived tropospheric temperature trends since 1979 are based on a combination of the midtropospheric (TMT) and lower stratospheric (TLS) channels of the microwave sounding unit (MSU) and the advanced microwave sounding unit (AMSU) (Fu et al. 2004; Johanson and $\mathrm{Fu} 2006$ ). Both the MSU and AMSU are instruments flown on National Oceanic and Atmospheric Administration (NOAA) polar-orbiting satellites as well as the National Aeronautics and Space Administration (NASA) Aqua satellite and the European Organisation for the Exploitation of Meteorological Satellites (EUMETSAT) MetOp-A satellite. Another synthetic lower tropospheric channel (TLT) has also been developed using observations from different view angles of MSU

Corresponding author address: Stephen Po-Chedley, Department of Atmospheric Sciences, Box 351640, University of Washington, Seattle, WA 98195.

E-mail:pochedls@uw.edu channel 2 (Spencer and Christy 1992a,b). TMT is a product based on MSU channel-2 near-nadir observations. A global TMT dataset was first produced and has since been maintained by the University of Alabama at Huntsville (UAH) team (Spencer and Christy 1990, 1992a,b; Christy et al. 1998, 2000, 2003).

Since the pioneering work of the UAH team, Remote Sensing Systems (RSS) and the NOAA team have produced TMT datasets based on the same satellite observations (Mears et al. 2003; Mears and Wentz 2009; Mears et al. 2011; Zou et al. 2006, 2009; Zou and Wang 2012). The procedure for merging individual satellites into a continuous, climate-quality TMT time series differs for each group and must account for a number of nonclimatic biases such as the diurnal cycle drift effect (e.g., Christy et al. 1997; Christy et al. 1998; 2000; Fu and Johanson 2005; Mears and Wentz 2005), biases due to the decay of satellite orbits (e.g., Wentz and Schabel 1998), frequency shifts in the radiometer passband (e.g., Zou and Wang 2012; Lu et al. 2011), and the influence of the instrument body temperature on the measured radiance (e.g., Christy et al. 1998, 2000; Prabhakara et al. 2000; Mears et al. 2003; Zou et al. 2006). As a result of differences in the merging procedure for the various MSU teams, global TMT trends from 1979 to 2009 differ 

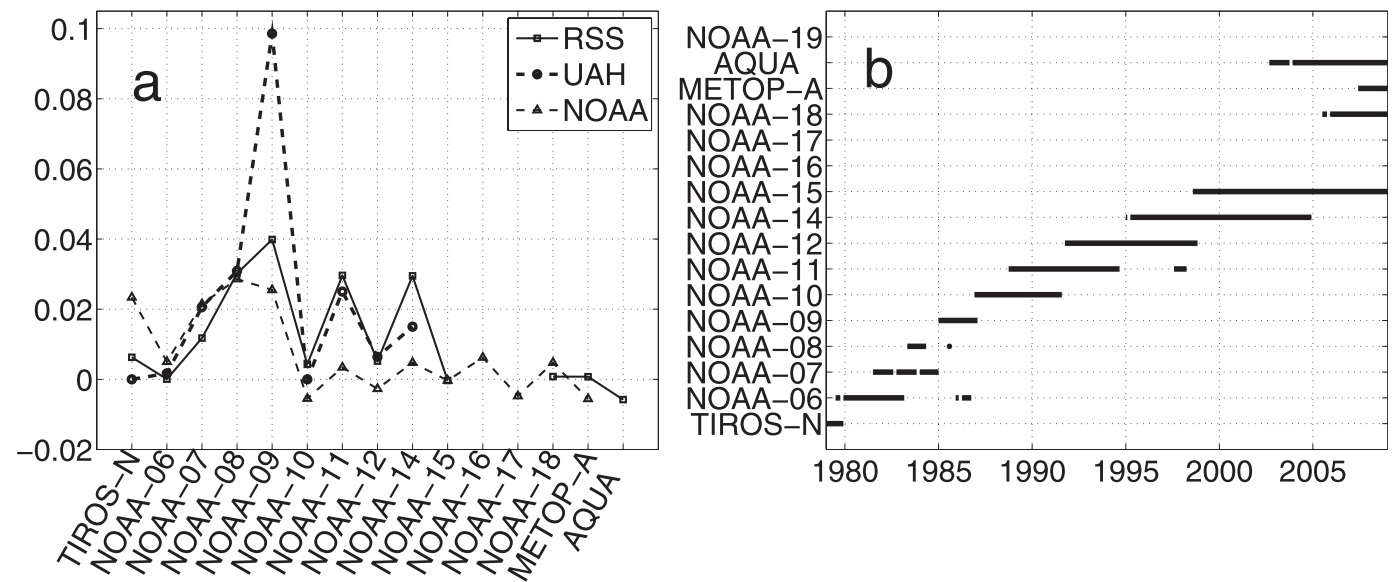

FIG. 1. (a) TMT warm target factors used for different MSU teams. (b) Satellites used in the RSS TMT merge (Mears and Wentz 2009). Note that the satellites used are different for the various MSU teams.

by more than a factor of 3 . The global TMT trends for 1979-2009 are 0.127, 0.080, and $0.038 \mathrm{~K} \mathrm{decade}^{-1}$ for NOAA, RSS, and UAH, respectively. Understanding the discrepancies in TMT trends among various teams is critically important to reliably derive tropospheric temperature trends based on satellite-borne MSU/AMSU observations (e.g., Karl et al. 2006).

Differences in the removal of the instrument body temperature effect for NOAA-9 have been highlighted as one of the most important differences between UAH and RSS, accounting for $\geq 50 \%$ of the TMT trend difference (Mears et al. 2003; Karl et al. 2006). The impact of the different methods to remove the instrument body effect has been considered as a part of the structural uncertainty that results from the application of a reasonable set of processing choices (Thorne et al. 2005a; Karl et al. 2006). Using radiosonde measurements as a reference, we show that the treatment of the instrument body temperature effect (i.e., warm target calibration) by UAH has a significant bias for the NOAA-9 satellite.

This article is organized as follows. Sections 2 and 3 describe the methodology and datasets used in this study, respectively. Section 4 attributes and quantifies the bias in the NOAA-9 warm target factor and its impact on the trend. A summary and conclusions follow in section 5 .

\section{Methodology}

UAH, RSS, and NOAA remove the effect of the instrument body temperature on the measured Earth radiance using an equation developed by Christy et al. (2000), which can be written as

$$
T_{\mathrm{MEAS}, i}=T_{o}+A_{i}+\alpha_{i} T_{\mathrm{TARGET}, i}+\Delta T_{\mathrm{MSU}, i}
$$

where $T_{\mathrm{MEAS}, i}$ is the measured brightness temperature for the $i$ th satellite, $T_{o}$ is the actual Earth brightness temperature, $A_{i}$ is a constant offset, $T_{\mathrm{TARGET}, i}$ is the temperature anomaly of the warm calibration target on the satellite as measured by platinum resistance thermometers, $\alpha_{i}$ is the warm target factor, and $\Delta T_{\mathrm{MSU}, i}$ represents unresolved residual errors (Mears et al. 2003). Note that $A_{i}$ is on the order of $0.01-1 \mathrm{~K}$ (Mears et al. 2003 ) and $\Delta T_{\mathrm{MSU}, i}$ is on the order of $0.1 \mathrm{~K}$ (Zou et al. 2009), but these values vary in time and space and by satellite.

The correction of the instrument body temperature effect is to account for postlaunch changes in the nonlinear operational calibration (e.g., Zou et al. 2006). Equation (1) is applied to co-orbiting satellite pairs in order to determine the warm target factor for the $i$ th and $j$ th satellite by minimizing the square of the measured brightness temperature differences for collocated observations averaged over 5 days (pentads):

$$
T_{\text {diff }}\left(t_{n}\right)=T_{\text {MEAS }, i}\left(t_{n}\right)-T_{\text {MEAS }, j}\left(t_{n}\right),
$$

where $T_{\text {diff }}$ is the difference in the brightness temperature measured by the two satellites (Christy et al. 2000; Mears et al. 2003).

Figure 1 shows the warm target factors used by different MSU teams for each satellite and the time periods for which each satellite is incorporated into the TMT product. NOAA and RSS use oceanic pentads to determine the warm target factor in order to minimize the potential influence of the diurnal cycle drift effect (Mears et al. 2003; Zou et al. 2009), whereas UAH uses both land and ocean pentads to determine the warm target factor. There is typically good agreement for the selection of the warm target factor between UAH and RSS. 
An important exception is for NOAA-9, when the RSS and UAH target factor differs by more than a factor of 2: 0.040 for RSS versus 0.099 for UAH (Dr. J. Christy 2011, personal communication; Mears and Wentz 2009). This difference arises because the UAH team does not consider short satellite overlaps, which reduces the number of pentad pairs used to determine the warm target factors (Mears et al. 2003). Target factors for the NOAA team starting with the NOAA-10 satellite are different in part because the team first addresses nonlinear calibration issues using simultaneous nadir overpasses of co-orbiting satellites and then applies the instrument body effect corrections (Zou et al. 2006, 2009; Zou and Wang 2010). The NOAA team warm target factor for the NOAA-9 satellite is 0.025 (Drs. C. Z. Zou and W. H. Wang 2011, personal communication). The large difference in the NOAA-9 target factor between $\mathrm{UAH}$ and RSS (NOAA) implies that one or more teams is over- or underestimating the influence of the warm target temperature on the measured Earth radiance. As such, artificial residuals will remain in the temperature time series.

We find that the difference between any two teams' TMT anomaly series is significantly correlated $(95 \%$ confidence) with the global mean NOAA-9 warm target temperature from January 1985 to February 1987 (26 months). For example, the correlation coefficient $(r)$ for UAH-NOAA and UAH-RSS versus $T_{\text {TARGET }}$ is -0.90 and -0.83 , respectively. This implies that the warm target calibration does explain some of the differences between the MSU datasets. As a result of the warm target temperature drift during NOAA-9's operational life, these differences will also affect the merged TMT trends. In this study, we utilize radiosondes as references to find biases in the warm target factor $\alpha_{i}$.

If we define the reported brightness temperature as the measured brightness temperature minus the constant offset and the influence of the instrument body effect (i.e., $T_{\mathrm{MSU}, i}=T_{\mathrm{MEAS}, i}-A_{i}-\alpha_{i} T_{\mathrm{TARGET}, i}$ ), then Eq. (1) becomes

$$
T_{\mathrm{MSU}, i}=T_{o}+\Delta T_{\mathrm{MSU}, i},
$$

which is simply the actual Earth brightness temperature plus the unresolved errors in the MSU/AMSU measurement.

We can similarly define the radiosonde temperature measurement as the sum of the actual Earth brightness temperature and some unresolved error:

$$
T_{R}=T_{o}+\Delta T_{R}
$$

where $T_{R}$ is the radiosonde measurement, $T_{o}$ represents the actual signal, and $\Delta T_{R}$ represents the measurement error of the radiosonde. By taking the difference of Eqs. (3) and (4), we have

$T_{\mathrm{MSU}}-T_{R}=\left(T_{o}+\Delta T_{\mathrm{MSU}}\right)-\left(T_{o}+\Delta T_{R}\right)$,

where the subscripts MSU and $R$ refer to MSU/AMSU and radiosonde measurements, respectively. This leaves

$$
T_{\mathrm{MSU}}-T_{R}=\Delta T_{\mathrm{MSU}}-\Delta T_{R} .
$$

Note that the MSU error may be written as $\Delta T_{\mathrm{MSU}}=$ $-\Delta \alpha_{i} T_{\mathrm{TARGET}, i}+\epsilon_{i}$, where $\epsilon_{i}$ represents any unresolved errors unrelated to the warm target calibration and $\Delta \alpha_{i}$ represents a bias in the warm target factor. The radiosonde measurement error (i.e., $\Delta T_{R}$ ) is unrelated to the satellite warm target temperature. We will examine the correlation between $T_{\mathrm{MSU}}-T_{R}$ (i.e., $\Delta T_{\mathrm{MSU}}-\Delta T_{R}$ ) and the warm target temperature $T_{\text {TARGET }}$. We expect no (a nonzero) correlation if the instrument body effect is (is not) removed from the MSU/AMSU dataset. Some of the problems that bias radiosondes, such as solar heating effects and instrument changes (e.g., Gaffen 1994; Sherwood et al. 2005), have no physical relationship with the warm target temperature and thus have little effect on our procedure. Note that by assuming that $\Delta T_{R}$ cannot explain the variance in $T_{\text {TARGET }}$ we are not assuming that $\Delta T_{R} \sim 0$. For our application radiosondes act as independent observations to remove the real signal of the Earth radiance.

\section{MSU and radiosonde datasets}

We focus our analysis on monthly TMT data during the NOAA-9 time period (January 1985-February 1987). In our comparison, we utilize UAH T2 (i.e., TMT) V5.3, RSS TMT V3.3, and NOAA TMT V2.0 (Christy et al. 2003; Mears and Wentz 2009; Zou and Wang 2012). For each gridded dataset we calculate anomalies based on a common reference period (1995-2005) to facilitate comparison.

Radiosondes will be used as an independent reference for the MSU/AMSU-derived datasets. We use station data from five global, homogenized, monthly mean radiosonde datasets provided by the University of Vienna [Radiosonde Innovative Composite Homogenization (RICH) and Radiosonde Observation Correction using Reanalysis (RAOBCORE V1.4); Dr. L. Haimberger (2011, personal communication); Haimberger (2007, 2008)], NOAA [Radiosonde Atmospheric Temperature Products for Assessing Climate (RATPAC-B); Free et al. (2005)], the Met Office Hadley Centre Atmospheric Temperatures, version 2 (HadAT2; Thorne et al. 2005b), and Sherwood et al. [Iterative Universal Kriging (IUK A and B); Sherwood (2007); Sherwood et al. (2008)]. We used these five datasets to demonstrate that our results are robust regardless of the radiosonde dataset used, even though each dataset was formed with different homogenization 
techniques and different sets of radiosonde observations. See the provided references for the station distribution and homogenization techniques for the various radiosonde datasets.

For the radiosonde data, we use the same reference period (1995-2005) to derive anomalies and apply a weighting function from RSS to monthly-mean data to produce synthetic MSU TMT brightness temperatures. For each radiosonde station within each product we required that at least $90 \%$ of the time series be available with enough data to fill in at least $85 \%$ of the weighting function in order to produce a time series for that station. As a result of these constraints, only a subset of each radiosonde dataset was used. In this study, we used 384 of 2881 radiosonde stations for RICH and RAOBCORE V1.4, 219 of 676 stations for HadAT2, 45 of 85 stations for RATPAC-B, and 451 of 527 stations for IUK A and B. If enough data existed for both the 0000 and 1200 UTC time series, the anomalies for each were averaged together to form a single time series for each station. For each radiosonde dataset, MSU data was temporally and spatially collocated with radiosonde station data to form corresponding MSU time series.

\section{Determining the bias in the NOAA-9 target factor}

\section{a. Quantifying the bias}

Since the NOAA-9 target factors are very different for each group, we expect that some fraction of the TMT anomaly series will be related to the warm target temperature for one or more MSU teams. We can rewrite Eq. (1) as

$$
T_{\mathrm{MEAS}, i}=T_{o}+A_{i}+\left(\alpha_{i, o}+\Delta \alpha_{i}\right) T_{\mathrm{TARGET}, i}+\epsilon_{i},
$$

where $\alpha_{i, o}$ is the optimized warm target factor and $\Delta \alpha_{i}$ is a measure of the over- or underestimate of the warm target factor. If $\Delta \alpha_{i} \neq 0$, residuals related to the warm target factor will remain in the TMT time series.

We examine difference time series for each MSU team's TMT product with a reference time series derived from radiosondes [see Eq. (6)]. If this difference time series over the NOAA-9 period (January 1985February 1987) is correlated with the global average warm target temperature, we can conclude that the warm target calibration for NOAA-9 is artificially affecting TMT. The slope of the temperature residuals versus the warm target temperature is a measure of the warm target factor bias $\Delta \alpha_{i}$.

In Table 1, we present the correlation coefficients for MSU - REFERENCE versus $T_{\text {TARGET, } 9}$ over the
TABLE 1. Correlation coefficients for MSU (column) REFERENCE (row) vs the global mean warm target temperature for NOAA-9 during January 1985 to February 1987. The radiosonde mean is the correlation coefficient of the mean of the five UAHREFERENCE time series vs the global warm target temperature for NOAA-9.

\begin{tabular}{lrrr}
\hline \hline REFERENCE & NOAA & \multicolumn{1}{c}{ RSS } & \multicolumn{1}{c}{ UAH } \\
\hline HadAT2 & -0.044 & -0.087 & $-0.404^{*}$ \\
IUK & 0.146 & 0.105 & $-0.443^{*}$ \\
RICH & -0.143 & -0.245 & $-0.536^{*}$ \\
RAOBCORE & -0.106 & -0.203 & $-0.510^{*}$ \\
RATPAC & -0.235 & -0.357 & $-0.758^{*}$ \\
Radiosonde mean & -0.077 & -0.166 & $-0.573^{*}$ \\
\hline
\end{tabular}

* Values are significant with $95 \%$ confidence.

NOAA-9 period. We see that the warm target factor is significantly related to the UAH TMT product, regardless of the reference dataset. RSS and NOAA are not significantly related to the warm target temperature for any of the radiosonde reference datasets.

In Fig. 2 we show the relationship for UAH REFERENCE versus $T_{\text {TARGET, } 9}$ over the NOAA-9 period. In this case, we averaged the five collocated (UAH - REFERENCE) time series and regressed this average time series against $T_{\text {TARGET,9. }}$. This method has the advantage of reducing random noise related to the different radiosonde datasets. This radiosonde mean estimate for $\Delta \alpha_{9}$ for UAH is $0.051 \pm 0.031$ (95\% confidence). We estimate the $\Delta \alpha_{9}$ value for UAH because it is significantly correlated with every radiosonde reference. The sign difference between the slope in Fig. 2 and $\Delta \alpha_{9}$ results because the instrument body effect correction is subtracted from the measured brightness temperature (the reported brightness temperature will depend on $T_{\text {TARGET }}$ through $-\Delta \alpha T_{\text {TARGET }}$ ).

In Table 2, we provide the $\Delta \alpha_{9}$ value for UAH compared to each reference dataset, which is the magnitude of the slope of the relationship between UAH REFERENCE and $T_{\text {TARGET,9. This value should be }}$ subtracted from $\alpha_{9}$ to correct the UAH TMT time series. Using our radiosonde mean estimate, we find that UAH overestimated the warm target factor for NOAA-9 by $0.051 \pm 0.031$. In calculating the confidence interval, we used the fit error from Fig. 2. This value compares favorably to the warm target factor difference for UAH minus RSS (NOAA). The warm target factor difference between UAH and RSS (UAH and NOAA) is $\Delta \alpha_{9}=$ $0.059\left(\Delta \alpha_{9}=0.073\right)$.

\section{b. The effect of the NOAA-9 warm target bias on the UAH TMT trend}

To estimate the effect of the NOAA- 9 warm target bias on the global mean TMT trend, we began by determining 


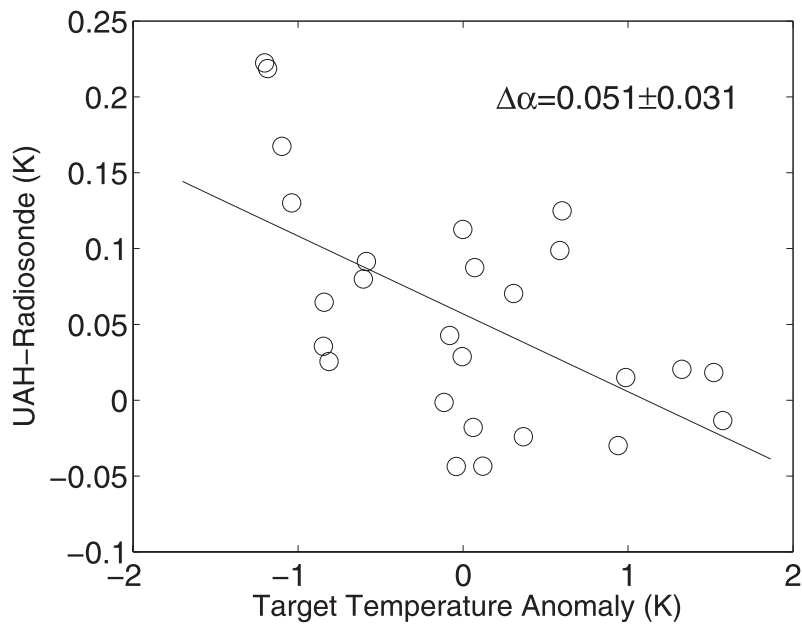

FIG. 2. Scatterplot of the mean of the five collocated UAH RADIOSONDE difference series vs the warm target temperature. Note that $\Delta \alpha=-$ slope because the $\alpha T_{\text {TARGET }}$ term is subtracted from the measured brightness temperature to obtain the calibrated UAH brightness temperature ( $\left.T_{\mathrm{MSU}}\right)$. The error is the $95 \%$ confidence interval in the fit.

the trend in the global mean warm target temperature during NOAA-9's operational period (January 1985-February 1987) using a least squares linear fit. For the global average warm target temperature, we obtain a trend of $1.15 \mathrm{~K} \mathrm{yr}^{-1}$. Its impact on the global UAH TMT product over NOAA-9 is then $-1.15 \mathrm{~K} \mathrm{yr}^{-1} \times \Delta \alpha_{9} \times t$, where $t$ is time in years starting from January 1985 . To estimate the impact of this bias on the long-term trend, we set a synthetic time series as zero from January 1979 through December $1984,-1.15 \mathrm{~K} \mathrm{yr}^{-1} \times \Delta \alpha_{9} \times t$ during January 1985 through February 1987, and $-1.15 \mathrm{~K} \mathrm{yr}^{-1} \Delta \alpha_{9}(26 / 12)$ for March 1987 through December 2009. We then take the least squares linear trend of this synthetic time series to estimate the impact on the long-term trend. Using this approach, we estimate the effect of the NOAA-9 target factor on the long-term UAH TMT trend as $-0.042 \mathrm{~K}$ decade $^{-1}$ (1979-2009). This estimate indicates that the global UAH TMT trends are artificially reduced by this bias.

In Fig. 3, we use the same procedure to estimate the spatial trend effect at each grid point because the $T_{\text {TARGET, } 9}$ drift is not spatially homogeneous. Spatial differences in Fig. 3 are due to differences in the target temperature drift over the $N O A A-9$ operational period, since we used a spatially constant $\Delta \alpha_{9}$ value (MSU teams use a constant value for $\alpha_{9}$ ). Fundamentally, the target temperature is related to the solar zenith angle, which influences the heating and cooling of the instrument (Zou and Wang 2012). The instrument body effect does not explain differences in land versus ocean trends for the different MSU/AMSU teams because the effect is
TABLE 2 . The $\Delta \alpha_{9}$ values and $95 \%$ confidence intervals derived from our least squares linear fit. These values are the magnitude of the slope of the linear relationship between UAH (column) REFERENCE (row) vs the global mean warm target temperature over the NOAA-9 operational period. This value should be subtracted from $\alpha_{9}$ to correct for the nonoptimal selection of warm target factor. The radiosonde mean is as in Table 1 and Fig. 2.

\begin{tabular}{lc}
\hline \hline REFERENCE & UAH $\Delta \alpha_{9}$ \\
\hline HadAT2 & $0.041 \pm 0.039$ \\
IUK & $0.038 \pm 0.032$ \\
RICH & $0.056 \pm 0.037$ \\
RAOBCORE & $0.051 \pm 0.036$ \\
RATPAC & $0.071 \pm 0.026$ \\
Radiosonde mean & $0.051 \pm 0.031$ \\
\hline
\end{tabular}

related to the nonlinear radiometer calibration and does not depend on the surface type (Mears et al. 2003). The pronounced striping in Fig. 3 may be a result of nonuniform sampling of the seasonal cycle over NOAA-9's life. A similar observation was noted by Mears et al. (2003) when looking at the differences between ascending and descending nodes of the satellite orbit.

Our global mean trend sensitivity to the NOAA-9 target factor is similar to that estimated by Mears et al. (2003). When the RSS team used the UAH NOAA-9 TMT target factor, they found a trend decrease of $0.073 \mathrm{~K} \mathrm{decade}^{-1}$. On the other hand, when the UAH team used the RSS target factor they found a trend increase of $0.05 \mathrm{~K} \mathrm{decade}^{-1}$ (Mears et al. 2003). Comparisons of the present result with those in Mears et al. (2003) differ in part because of version changes, including target factor changes for both groups. We also expect the trend effect of the NOAA-9 target factor to be smaller now since the time series is longer. We find a UAH trend increase of $0.064 \mathrm{~K}^{\text {decade }}{ }^{-1}$ when the trend spans 1979-2002, consistent with the findings in Mears et al. (2003). While our estimate of the UAH TMT trend sensitivity to the warm target factor is similar to estimates by the UAH and RSS teams, our study indicates that the UAH team will need to incorporate an

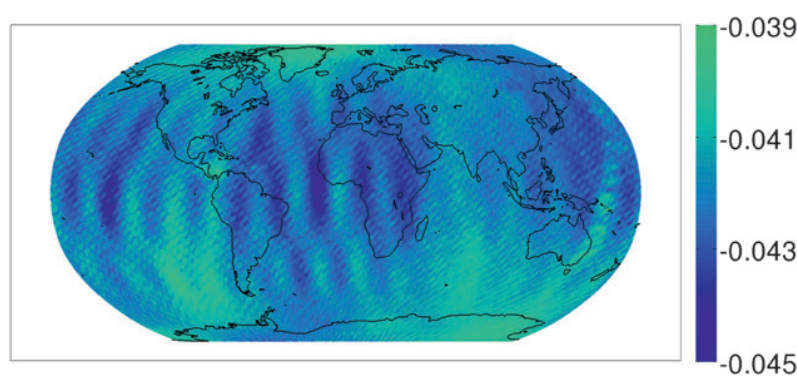

FIG. 3. Estimate of the spatial impact of the UAH NOAA-9 warm target bias on UAH TMT trends $\left(\mathrm{K} \mathrm{decade}^{-1}\right)$. 
optimal NOAA-9 target factor into their merging procedure for an accurate trend estimate.

Current global TMT trends for NOAA, RSS, and UAH are 0.127, 0.080, and $0.038 \mathrm{~K} \mathrm{decade}^{-1}$ (1979-2009). By correcting the bias in the UAH warm target factor, the global UAH TMT trend becomes $0.080 \mathrm{~K} \mathrm{decade}^{-1}$, which effectively eliminates the global UAH and RSS trend difference and reduces the global UAH and NOAA trend difference by $47 \%$.

A key consideration for tropospheric trend interpretation is the contamination of the TMT product by the stratosphere (e.g., Fu and Johanson 2005; Johanson and Fu 2006). Using a combination of TMT and TLS (referred to as T24) (Fu et al. 2004; Johanson and Fu 2006), the UAH T24 trend will increase if this bias is taken into account. We carried out an identical analysis for TLT, but there was no statistically significant relationship between UAH (RSS) minus REFERENCE and the global warm target temperature during the NOAA-9 period for four of five radiosonde references. This result is unsurprising because the TLT product is a linear combination of signals from different view angles, which amplifies noise by a factor of 3 compared to TMT (Hurrell and Trenberth 1998). Importantly, UAH uses the same target factors for the TLT product (Christy et al. 2000) (RSS uses $\alpha_{9}=0.049$ ) and there is a significant relationship for UAH minus RSS TLT versus $T_{\text {TARGET }, 9}$ ( $r=0.64, \Delta \alpha_{9}=0.054,95 \%$ confidence). The NOAA-9 warm target bias thus has a similar effect on the UAH TLT product.

\section{Summary and conclusions}

Using radiosondes as references, we were able to attribute a bias in the NOAA-9 warm target factor to the $\mathrm{UAH}$ team and quantify its magnitude. The bias was statistically significant and compared well with the UAH minus RSS (NOAA) warm target value differences. We estimate that the UAH NOAA-9 warm target bias is $0.051 \pm 0.031$. Accounting for this problem, the global UAH TMT trend increases by an estimated 0.042 K decade ${ }^{-1}$ (1979-2009), which reconciles the current global trend difference between UAH and RSS. Since the UAH TMT warm target factors are also used for the TLT product (Christy et al. 2000) and the T24 product utilizes TMT, T24 and TLT trends are also affected by this bias.

There is likely a residual bias related to the NOAA and/or RSS NOAA-9 warm target factor, even though the present study indicates that RSS and NOAA have no significant biases. Note that TMT residuals for RSS NOAA are significantly related to $T_{\text {TARGET, } 9}(r=$ $-0.501)$. This indicates that some of the differences between RSS and NOAA during this time are related to the instrument body temperature effect, but because neither dataset is significantly related to the warm target temperature when using radiosondes as references, the bias is too small to be quantified by radiosonde observations.

Creating climate-quality satellite temperature datasets is a challenging process that requires constant attention as new biases are discovered (e.g., Wentz and Schabel 1998; Christy et al. 2000; Fu and Johanson 2005; Mears and Wentz 2005). Independent measurements of atmospheric temperature such as those from radiosondes will continue to be an important tool in evaluating satellite temperature products over limited time periods.

Acknowledgments. This work was supported by the National Science Foundation Graduate Research Fellowship (DGE-0718124), NOAA Grant NA08OAR4310725, and NESDIS-NESDISPO-2009-2001589 (SDS-09-15).

\section{REFERENCES}

Christy, J. R., R. W. Spencer, and W. D. Braswell, 1997: How accurate are satellite 'thermometers'? Nature, 389, 342-342. , and E. S. Lobl, 1998: Analysis of the merging procedure for the MSU daily temperature time series. J. Climate, 11, 2016-2041.

, - - and W. D. Braswell, 2000: MSU tropospheric temperatures: Dataset construction and radiosonde comparisons. J. Atmos. Oceanic Technol., 17, 1153-1170.

,,-- W. B. Norris, W. D. Braswell, and D. E. Parker, 2003: Error estimates of version 5.0 of MSU-AMSU bulk atmospheric temperatures. J. Atmos. Oceanic Technol., 20, 613-629.

— , and Coauthors, 2010: What do observational datasets say about modeled tropospheric temperature trends since 1979 ? Remote Sens., 2, 2148-2169, doi:10.3390/rs2092148.

Free, M., D. J. Seidel, J. K. Angell, J. Lanzante, I. Durre, and T. C. Peterson, 2005: Radiosonde atmospheric temperature products for assessing climate (RATPAC): A new data set of largearea anomaly time series. J. Geophys. Res., 110, D22101, doi:10.1029/2005JD006169.

Fu, Q., and C. M. Johanson, 2005: Satellite-derived vertical dependence of tropical tropospheric temperature trends. Geophys. Res. Lett., 32, L10703, doi:10.1029/2004GL022266.

$\longrightarrow,-$ S. G. Warren, and D. J. Seidel, 2004: Contribution of stratospheric cooling to satellite-inferred tropospheric temperature trends. Nature, 429, 55-58.

_- S. Manabe, and C. M. Johanson, 2011: On the warming in the tropical upper troposphere: Models versus observations. Geophys. Res. Lett., 38, L15704, doi:10.1029/2011GL048101.

Gaffen, D. J., 1994: Temporal inhomogeneities in radiosonde temperature records. J. Geophys. Res., 99 (D2), 3667-3676.

Haimberger, L., 2007: Homogenization of radiosonde temperature time series using innovation statistics. J. Climate, 20, 1377-1403. , C. Tavolato, and S. Sperka, 2008: Toward elimination of the warm bias in historic radiosonde temperature records-Some new results from a comprehensive intercomparison of upperair data. J. Climate, 21, 4587-4606. 
Hurrell, J. W., and K. E. Trenberth, 1998: Difficulties in obtaining reliable temperature trends: Reconciling the surface and satellite Microwave Sounding Unit records. J. Climate, 11, 945-967.

Johanson, C. M., and Q. Fu, 2006: Robustness of tropospheric temperature trends from MSU channels 2 and 4. J. Climate, 19, 4234-4242.

Karl, T. R., S. J. Hassol, C. D. Miller, and W. L. Murray, Eds., 2006: Temperature trends in the lower atmosphere: Steps for understanding and reconciling differences. Synthesis and Assessment Product 1.1, Climate Change Science Program and the Subcommittee on Global Change Research, 164 pp. [Available online at http://www.climatescience.gov/Library/sap/sap1-1/ finalreport/sap1-1-final-all.pdf.]

Lu, Q., W. Bell, P. Bauer, N. Bormann, and C. Peubey, 2011: Characterizing the $F Y-3 A$ microwave temperature sounder using the ECMWF model. J. Atmos. Oceanic Technol., 28, 1373-1389.

McCarthy, M. P., H. A. Titchner, P. W. Thorne, S. F. B. Tett, L. Haimberger, and D. E. Parker, 2008: Assessing bias and uncertainty in the HadAT-adjusted radiosonde climate record. J. Climate, 21, 817-832.

Mears, C. A., and F. J. Wentz, 2005: The effect of diurnal correction on satellite-derived lower tropospheric temperature. Science, 309, 1548-1551, doi:10.1126/science.1114772.

$\longrightarrow$, and —, 2009: Construction of the RSS v3.2 atmospheric temperature dataset from the MSU and AMSU microwave sounders. J. Atmos. Oceanic Technol., 26, 1493-1509.

— M. C. Schabel, and F. J. Wentz, 2003: A reanalysis of the MSU channel 2 tropospheric temperature record. J. Climate, 16, 3650-3664

— F. J. Wentz, P. Thorne, and D. Bernie, 2011: Assessing uncertainty in estimates of atmospheric temperature changes from MSU and AMSU using a Monte Carlo estimation technique. J. Geophys. Res., 116, D08112, doi:10.1029/2010JD014954.

Prabhakara, C., R. Iacovazzi Jr., J.-M. Yoo, and G. Dalu, 2000: Global warming: Evidence from satellite observations. Geophys. Res. Lett., 27, 3517-3520.

Santer, B. D., and Coauthors, 2008: Consistency of modelled and observed temperature trends in the tropical troposphere. Int. J. Climatol., 28, 1703-1722, doi:10.1002/joc.1756.

Sherwood, S. C., 2007: Simultaneous detection of climate change and observing biases in a network with incomplete sampling. J. Climate, 20, 4047-4062.
J. R. Lanzante, and C. L. Meyer, 2005: Radiosonde daytime biases and late 20th century warming. Science, 309, 1556-1559, doi:10.1126/science.1115640.

— C. L. Meyer, R. J. Allen, and H. A. Titchner, 2008: Robust tropospheric warming revealed by iteratively homogenized radiosonde data. J. Climate, 21, 5336-5352.

Solomon, S., D. Qin, M. Manning, M. Marquis, K. Averyt, M. M. B. Tignor, H. L. Miller Jr., and Z. Chen, Eds., 2007: Climate Change 2007: The Physical Science Basis. Cambridge University Press, 996 pp.

Spencer, R. W., and J. R. Christy, 1990: Precise monitoring of global temperature trends from satellites. Science, 247, 15581562, doi:10.1126/science.247.4950.1558.

$\longrightarrow$, and $-1992 \mathrm{a}$ : Precision and radiosonde validation of satellite gridpoint temperature anomalies. Part I: MSU channel 2. J. Climate, 5, 847-857.

$\longrightarrow$, and $-1992 \mathrm{~b}$ : Precision and radiosonde validation of satellite gridpoint temperature anomalies. Part II: A tropospheric retrieval and trends during 1979-90. J. Climate, 5, 858-866.

Thorne, P. W., D. E. Parker, J. R. Christy, and C. A. Mears, 2005a: Uncertainties in climate trends: Lessons from upper-air temperature records. Bull. Amer. Meteor. Soc., 86, 1437-1442.

,-- , S. F. B. Tett, P. D. Jones, M. McCarthy, H. Coleman, and P. Brohan, 2005b: Revisiting radiosonde upper air temperatures from 1958 to 2002. J. Geophys. Res., 110, D18105, doi:10.1029/2004JD005753.

Wentz, F. J., and M. Schabel, 1998: Effects of orbital decay on satellite-derived lower-tropospheric temperature trends. $\mathrm{Na}$ ture, 394, 661-664.

Zou, C.-Z., and W. Wang, 2010: Stability of the MSU-derived atmospheric temperature trend. J. Atmos. Oceanic Technol., 27, 1960-1971.

$\longrightarrow$, and - , 2012: Inter-satellite calibration of AMSU-A observations for weather and climate applications. J. Geophys. Res., 116, D23113, doi:10.1029/2011JD016205.

- M. D. Goldberg, Z. Cheng, N. C. Grody, J. T. Sullivan, C. Cao, and D. Tarpley, 2006: Recalibration of microwave sounding unit for climate studies using simultaneous nadir overpasses. J. Geophys. Res., 111, D19114, doi:10.1029/ 2005JD006798.

- M. Gao, and M. D. Goldberg, 2009: Error structure and atmospheric temperature trends in observations from the Microwave Sounding Unit. J. Climate, 22, 1661-1681. 